Guillermo Schmidhuber de la Mora*

Universidad de Guadalajara, Guadalajara, México

Olga Martha Peña Doria**

Universidad de Guadalajara, Guadalajara, México

\title{
LAS IDEAS DE JUAN EUSEBIO NIEREMBERG Y ATHANASIUS KIRCHER EN LA OBRA DE SOR JUANA INÉS DE LA CRUZ, LA AUTORA NOVOHISPANA
}

\author{
Artículo científico original \\ UDC 821.134.2(72)-14 \\ https://doi.org/10.18485/kkonline.2020.11.11.12
}

\begin{abstract}
El pensamiento teológico y la comprensión cosmológica de Juan Eusebio Nieremberg y Athanasius Kircher, afamados jesuitas del siglo XVII, tuvieron gran influencia en los escritos de Sor Juana Inés de la Cruz (1648-1695), la autora cumbre del Barroco mexicano; la teología de la Belleza de Nieremberg debió impactar en su búsqueda personal de mujer pensante, y por otra parte, la misma escritora citó ampliamente a Kircher. El presente artículo cita las veces que sus ideas dejaron huella en los escritos de Sor Juana. Se incluye un análisis del romance 50 de Sor Juana en que se descifra su encriptado utilizando las técnicas musicales de Kircher.
\end{abstract}

Palabras Clave: Sor Juana Inés de la Cruz, Juan Eusebio Nieremberg, Athanasius Kircher, Literatura novohispana, Barroco Hispanoamericano.

La escritora novohispana sor Juana Inés de la Cruz (1648-1695) ha tenido en los últimos años intensa atención crítica sobre su obra y búsquedas para esclarecer su biografía; sin embargo, menos se ha escrito sobre su pensamiento y su perenne interés de la teología (Schmidhuber y Peña Doria, 131-9). El presente artículo trata sobre dos de los intelectuales europeos que más influyeron en las ideas de sor Juana Inés de la Cruz: el reconocido teólogo español Juan Eusebio Nieremberg (Madrid 1595-Ibid 1658), de quien aprendió la teología de la Belleza, y el alemán Athanasius Kircher (Fulda en Hesse 1602-Roma 1680), a quien citó en dos poemas y en la misiva conocida como la Respuesta a sor Filotea de la Cruz, y de quien aprendió el orden cósmico que aplicó en su poema Primero sueño. Ambos pensadores pertenecieron a la Compañía de Jesús y gozaron de gran prestigio en el Imperio español del siglo XVII.

\footnotetext{
* Universidad de Guadalajara, Guadalajara, México, Av Juárez 976, Col Americana, Americana, 44160 Guadalajara, Jal., Mexico, schmidhuberg@gmail.com.

** Universidad de Guadalajara, Guadalajara, México, Av Juárez 976, Col Americana, Americana, 44160

Guadalajara, Jal., Mexico.
} 


\section{Juan Eusebio Nieremberg}

Es notable la concordancia en ideas de sor Juana con el pensamiento de Juan Eusebio Nieremberg; ${ }^{1}$ ¿Cómo llegaría a conocer la monja a este afamado teólogo español? El confesor de sor Juana y también jesuita, Antonio Núñez de Miranda, dejó testimonio en sus propios escritos con repetidas citas de libros de Nieremberg, como lo ha demostrado Pamela Kirk (artículo inédito), quien apunta que lo alabó seis veces como autor espiritual, con la mención de cuatro de sus tratados. ${ }^{2}$

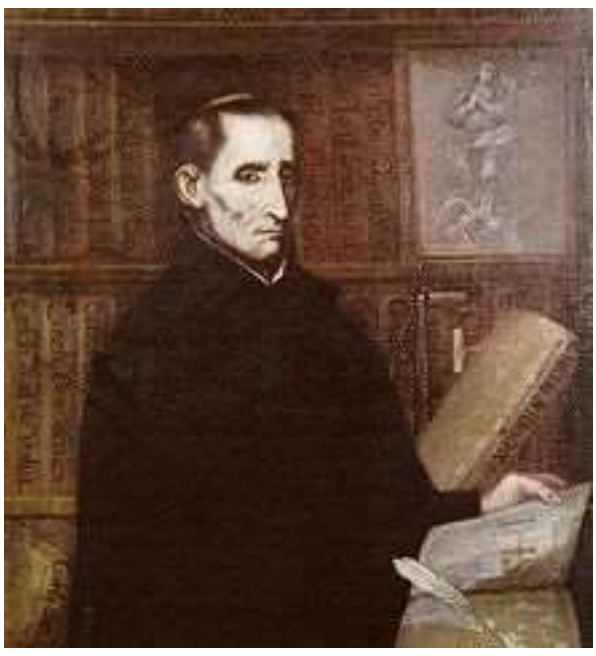

Juan Eusebio Nieremberg

No quedó testimonio explícito en la obra de sor Juana de una lectura de los tratados teológicos de Nieremberg, pero inaceptable es el aceptar que le fueran desconocidos. Bravo Arriaga (El discurso de la espiritualidad dirigida, 1991, 68) ha probado la cercanía de algunos textos del confesor de sor Juana con escritos de ascetismo monacal de Nieremberg:

Es importante destacar la relevancia del escrito de Nieremberg [Practica del Catecismo Romano y Doctrina Cristiana, Madrid 1734], pues es uno de los autores cuya presencia es constante en las obras de Núñez de Miranda. Su influencia se

\footnotetext{
${ }^{1}$ La influencia de Nieremberg en sor Juana ha sido señalada con diferentes aproximaciones: Olivares Zorrilla (2001: 145-160; 2009: 149-165); Bravo Arriaga (2001); Beuchot Puente (2001); y Pamela Kirk (artículo inédito), entre otros.

${ }^{2}$ Seis citas de Nieremberg en Daños del pecado venial, y granjeria spiritual en Comulgador, y explicación de la regla 18 de la Congregación de la Purísima, que es de la confesión, y comunión (México: Viuda de M. De Ribera, 1714); una cita en Día bueno, y entero, con todas sus obras, reglas y obligaciones: de un congregante de la Purísima (México: Viuda de Calderón, 1667); en su primera traducción de los Ejercicios Ignacianos para monjas (1665) cita al "Padre Juan Eusebio"; y en una versión más extensa titulada Exercicios espirituales de San Ignacio acomodados al estado, y profesión religiosa, de las señoras vírgenes, esposas de Christo (1695), recomienda la lectura de libros de Nieremberg y hace referencia una vez a Hermosura de Dios y cinco veces a De la Diferencia entre lo temporal y eterno (Madrid 1640).
} 
percibe en la reiterada recomendación que el jesuita novohispano hace de los textos del jesuita español.

Palpable es el paralelismo de la obra de sor Juana con el pensamiento de Nieremberg. Especialmente notable es la concordancia de algunos de sus textos como el siguiente texto-espejo en que sor Juana parafrasea un texto de Nieremberg, como ha sido apuntado sapientemente Rocío Olivares (2001: 147-48):

Respuesta a sor Filotea de la Cruz, de sor Juana:

Nada veía sin refleja: nada oía sin consideración, aun en las cosas más menudas y materiales; porque cono no hay criatura, por baja que sea, en que no se conozca el me fecit Deus, no hay alguna que no pasme el entendimiento... [Respuesta a sor Filotea de la Cruz, Obras Completas, vol. IV, 458.]

De Nieremberg:

Así pasa, que aunque cada naturaleza tenga mucho que admirar, pero juntadas todas, viendo como asientan y corresponden una con otras, armada ya esta estatua del mundo, este simulacro de Dios, es cosas que pasmar, y mucha más cuando se le considera que no tolo todas en una se eslabonan, sino todas en todas, y cada una en todas, y todas en cada una, respondiéndose de mil modos, y en cada una, y en todas está esmaltado un bulto de Dios, un rostro de su artífice con diferentes visos de sus perfecciones, que por todas partes se ve y se lee Deus me fecit. (Obras filosóficas 1686)

Una concordancia indudable. Además, sorprendente resulta el comprobar que la metáfora fundamental del auto de sor Juana, Divino Narciso: el género humano fue creado a imagen y semejanza de su creador, por eso Cristo/Narciso se enamora de su propia imagen reflejada en su criatura. Esta idea había sido escrita por Nieremberg con anterioridad a que sor Juana creara su Auto como se comprueba en su tratado sobre mitología escrito en latín, Sigalión (1531), en cuyo texto cita a Narciso y a Eco, como apunta Rocío Olivares $(2009,9)$ :

En su libro, entre diversos mitos, Nieremberg explica las cualidades anagógicas de los personajes de Eco y Narciso. Sigalión pregunta, "¿a quién ama Eco? Al bellísimo Narciso. ¿Quién es Narciso? Quien se ve contemplado de sí y no desea nada fuera de sí mismo. La sabiduría es conocerse, una cosa bellísima, plena y contenta de sí misma". De tal suerte, nos dice Nieremberg, Eco es el filósofo siempre sediento de saber que sólo repite lo que alcanza de la sabiduría divina.

Concordancias que no pueden ser explicadas por la simple casualidad.

Nieremberg estudió la Divinidad a partir de su atributo de la hermosura y escribió sus consideraciones en su libro De la hermosura de Dios y su amabilidad por las 
infinitas perfecciones del ser divino (1651; citada en, 1957, vol. 2, 307). Su pensamiento se fundamentó en las definiciones de lo hermoso de Platón que él mismo escribe: "Lo hermoso es un resplandor y rayo de lo bueno en las cosas que percibe la vista, el oído y el entendimiento" y de Aristóteles: Armonía, proporción y orden; y continuó con la exposición de las ideas del filósofo neoplatónico Plotino, del místico escocés Ricardo de San Víctor y de los santos Agustín, Ambrosio, Anselmo, Bernardo, Crisóstomo, Dionisio Areopagita, y otros exégetas. El tratado de Nieremberg constituye la manifestación última del misticismo clásico en la Literatura Española. La conclusión de este tratado es con las siguientes palabras:

Dice más San Dionisio: que lo hermoso es causa eficiente, y final, y ejemplar de todas las cosas. Lo primero es causa eficiente, porque la hermosura de Dios es infinitamente perfecta, ha de ser por consiguiente fecundísima, muy eficaz y obradora; así como las demás cosas, cuando están en estado imperfecto y diminuto, son estériles, sin comunicarse a otras; porque toda su virtud recogen en sí, teniendo primero cuenta con su aumento y perfección que con la comunicación de ella [...] Finalmente, advierte San Dionisio cuán digna sea de amar la Hermosura del Creador, porque verdaderamente no sólo es amable por ser tan hermosa, sino también por ser hermosas las criaturas; así con muy doblados títulos debemos amar a Dios por su Hermosura increada, y por ser causa de las hermosuras creadas. Y si la hermosura creada se suele amar sin interés, sin haber recibido beneficio della ni esperarle, ¿cómo debe ser amada aquella Hermosura, que es infinita en sí, y nos ha hecho infinitos beneficios, dándonos el ser, conservándole, perfeccionándole y beatificándole, haciendo tan hermosas las creaturas, y algunas tan sobre toda hermosura natural, que les dé participación de su Ser divino, de su gloria y bienaventuranza eterna? (1904, 158-59 y 16465)

La Hermosura es atributo definitorio de la Divinidad y permanece en la Naturaleza y el Cosmos, ambos entendidos por sor Juana y Nieremberg como destellos de lo Divino. Las consideraciones teológicas sorjuaninas quedaron desperdigadas en sus tres autos, sus 22 villancicos y explícitamente en la Carta Athenagorica. Estas consideraciones teológicas llevaron al crítico y sacerdote George Tavard (1991) a titular su libro sobre el pensamiento de sor Juana, La primera teóloga mexicana.

\section{Athanasius Kircher}

Kirkero - la versión latina del apellido- fue polígrafo y musicólogo; su ingresó a la Compañía de Jesús fue en 1618 Enseñó música, matemáticas, lenguas orientales y filosofía, en el colegio de Würzburg. Fue el primer europeo que estudió los jeroglíficos egipcios. Investigó el magnetismo y lo aplicó como medida curativa. Como secretario, acompañó al cardenal Federico de Sajonia a Malta. Fue catedrático de hebreo y 
matemáticas en Roma, en donde murió en 1680, como lo han escrito Paula Findlen (2004) y Thomas Woods (2005).

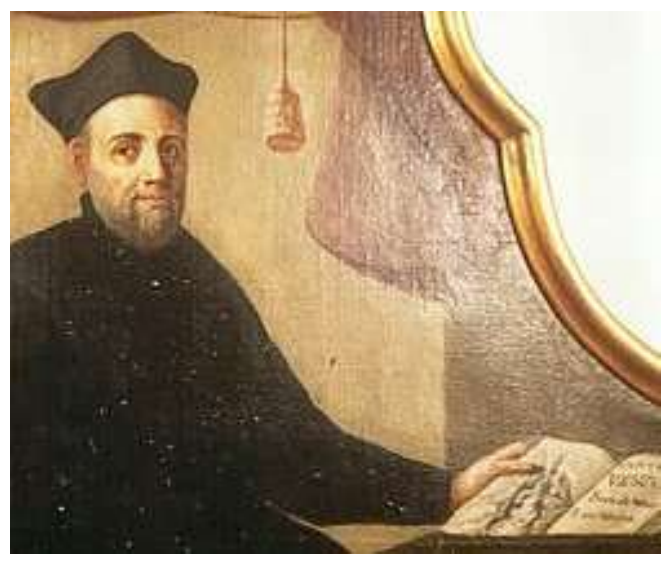

Athanasius Kircher

Octavio Paz (1994, 224-39) cita a Kircher como una de las fuentes del posible hermetismo neoplatónico de sor Juana. Además, en el retrato de sor Juana del pintor Miguel Cabrera, entre los libros pintados aparece el título de uno con el nombre legible de Kirqueri Opera, testimonio pintado en 1751 de su cercanía a la obra de este jesuita. La primera cita sorjuanina de Kircher es en el soneto 193, dedicado al virrey Marques de la Laguna:

Vuestra edad, gran señor, en tanto exceda A la capacidad que abrazo el cero Que la combinatoria de Kirchero Multiplicar su cantidad no pueda [...] (OC, vol. I, 302)

Además, pertenecen a este sabio alemán algunas de las imágenes descritas por la autora en Primero sueño, como la linterna mágica, que es considerada invento de Kircher, y algunas descripciones del cosmos geocéntrico. Como lo afirma Verónica Grossi: "El Primero Sueño [...] combina ciencia y poesía al incorporar ideas provenientes de la obra egiptóloga de Kircher, Oedipus Aegyptiacus (Roma, 1653), como en su mención en el poema de la 'linterna mágica', aparato nuevo que proyectaba imágenes luminosas" $(2007,38)$. Esta referencia se refiere a los versos 873 a 886 de Primero Sueño:

Así linterna mágica, pintadas representa fingidas en la blanca pared varias figuras, 
de la sombra no menos ayudadas

que de la luz: que en trémulos reflejos

los competentes lejos

guardando de la docta perspectiva,

en sus ciertas mensuras

de varias experiencias aprobadas,

la sombra fugitiva,

que en el mismo esplendor se desvanece,

cuerpo finge formado,

de todas dimensiones adornado,

cuando aun ser superficie no merece.

Anteriormente, Georgina Sabat-Rivers ya había apuntado la cercanía sorjuanina con las ideas de Kircher:

Todavía más que sus ideas sobre armonía, sinestesia, colores, luz, perspectiva, pirámides y jeroglíficos, toda la mentalidad del padre Kircher podrían haber actuado de una manera incitante y seductora sobre nuestra poetisa. La agradable conciliación entre exactitud y entusiasmo, subordinación y crítica, tal como él solía realizarla - por cierto en detrimento de su posterior reputación científica-, debía ser algo sumamente reconfortante para el espíritu poéticamente conmovido de Sor Juana, ya que se producía en una mente tan elevada. $(1977,91)$

Sor Juana (Obras completas, vol. IV, 450, línea 420-24; citado por Strasser, 2007: nota xxi), en su Respuesta a sor Filotea de Cruz, escribió el nombre de Kircher:

Es la cadena que fingieron los antiguos que salía de la boca de Júpiter, de donde pendían todas las cosas eslabonadas unas con otras. Así lo demuestra el R. P. Atanasio Quirqueiro en su curioso libro De Magnete. Todas las cosas salen de Dios, que es el centro a un tiempo y la circunferencia de donde salen y donde paran todas las líneas criadas.

La referencia es a dos libros de Kircher: Magnes, sive de arte magnetica opus tripartitvm (Rome 1641) y Magneticum naturae regnum (Amsterdam 1667).

En la Loa de Amor es más laberinto sor Juana experimenta con la estructura dramática a manera de las teorías musicales de Kircher, según están expuestas en su Musurgia universalis (Roma, 1650); libro de teoría musical que define la música como un arte de combinaciones matemáticas (Musurga combinatoria). La siguiente combinación con las letras A, $\mathbf{R}$ y $\mathbf{O}$ es un ejemplo presentado por este musicólogo alemán: 


$\begin{array}{llllll}1 & 2 & 3 & 4 & 5 & 6 \\ \text { ORA } & \text { OAR } & \text { ROA } & \text { RAO } & \text { AOR } & \text { ARO }\end{array}$

Con tres letras, se logran seis combinaciones (Musurgia universalis, tomo 2, 3). El siguiente es otro paradigma de Kircher (Tomo 2: 5), con cuatro letras: A, M, E y N, se logran 24 combinaciones:

$\begin{array}{llllll}\text { AMEN } & \text { ANEM } & \text { MEAN } & \text { EAMN } & \text { ENAM } & \text { NMAE } \\ \text { AMNE } & \text { ANME } & \text { MENA } & \text { EANM } & \text { ENMA } & \text { NMEA } \\ \text { AEMN } & \text { MAEN } & \text { MNAE } & \text { EMAN } & \text { NAME } & \text { NEMA } \\ \text { AENM } & \text { MANE } & \text { MNEA } & \text { EMNA } & \text { NAEM } & \text { NEAM }\end{array}$

En la Loa de su comedia Amor es más laberinto, los parlamentos siguen un orden combinatorio como puede comprobarse en el cuadro siguiente que enlista el orden de parlamento. La estructura dramática presenta siete grupos que separan los parlamentos a imitación del arte combinatorio musical, según lo expuesto en Musurgia universalis. Así sor Juana aplicó lo aprendido en los escritos de Kircher. Los diálogos de la Loa están dispuestos como en una partitura en donde cada parlamento fuera una intervención de un instrumento. Sor Juana experimenta en sus Autos Sacramentales con la asignación de parlamentos con combinaciones a manera Kircherana, aunque con intentos menores. En cuanto al interés de sor Juana por la música, hay que recordar que una de sus obras perdidas es el estudio musical titulado "El Caracol," como es informado por la misma autora en el romance 21 "Después de estimar mi amor" (Obras completas, vol. 1: 64), y como fue apuntado por Diego Calleja en su biografía de sor Juana (Fama y obras sin núm.). También Kircher utiliza la figura del caracol para explicar la armonía musical; acaso el manuscrito sorjuanino perdido es una elaboración sobre este concepto Kircherano. En el siguiente análisis, los personajes son identificados por las siglas: Invierno, Estío, Otoño, Verano, además, se incluye edad y Música; es decir, I, E, O, V, e, M: 


\begin{tabular}{|cccccccc|}
\hline 1 & 2 & 3 & 4 & 5 & 6 & 7 \\
IEVO & M & VOEI & I & M & IVM & E \\
IVOE & VM & e & Todos & e M & OM & Todos \\
Todos & OM & OIEV & V & e M & IEVOM & M \\
e & EM & e & Todos & e M & IM & \\
IEOV & IM & EIVO & E & e M & EM \\
e & & e & Todos & e M & VM \\
IVEI3 & & VIOE & O & & OM \\
& & Todos & & & \\
\end{tabular}

La tercera cita de Sor Juana (Obras Completas, vol. I, 158) de Kichner es al final del romance 50, texto que fue escrito a manera de misiva al "caballero peruano que la aplaude" (cuyo nombre era Luis Antonio Oviedo y Herrera, Conde de la Granja):

Pues si la Combinatoria, en que a veces Kirkerizo, en el cálculo no engaña y no yerra en el guarismo [...]

El romance 50 de sor Juana esconde un juego anagramático y criptográfico que oculta lúdicamente el nombre del destinatario, el Conde de la Granja. El arte combinatorio de Kircher propone las permutaciones de notas musicales o letras; sor Juana contó con un universo de $6 !=720$ posibilidades con las seis letras de "GRANJA" que se identifican abajo con colores (Schmidhuber 2015):

Romance 50 de Sor Juana

Allá va, aunque no debiera

(incógnito Señor mío),

la respuesta de portante

a los versos de camino.

No debiera: porque cuando se oculta el hombre, es indicio

que no habéis querido ser hombre de nombre conmigo; por lo cual, fallamos que fuera muy justo castigo, sin perdonaros por pobre, dejaros por escondido.

Pero el diablo del Romance tiene, en su oculto artificio,
Híceles mi invocación, tal, cual fue Apolo servido, con necesitadas plagas

y con clamores mendiGos; GANARJ = GRANJA

y ellAs, coN piedAd de veRme

tan hambrienta de eJercicios,

tan sedienta de conceptos

y tan desnuda de estilos, ejercitaron las obras, que nos pone el Catecismo, de Misericordia, viendo que tanto las necesito.

Dióme la Madama Euterpe un retazo de Virgilio,

\footnotetext{
${ }^{3}$ Para conservar las combinaciones debe ser IVEO, quitando la repetición del Invierno y substituyéndolo por Otoño. Nótese que el diálogo de la Edad ("Yo a todo el empeño salgo") es un agregado para introducir la información de la celebración "de dar años" al virrey (Sor Juana Inés de la Cruz, Obras completas, vol. 4: 194), ya que rompe con la estructura inspirada en las combinaciones matemáticas que debieron ser escritas con anticipación.
} 
en cada copla una fuerza

y en cada verso un hechizo.

Tiene un agrado tirano, que, en lo blando del estilo, el que suena como ruego apremia como dominio.

Tiene una virtud, de quien el vigor penetrativo se introduce en las potencias, sin pasar por los sentidos.

Tiene una altiva humildad, que con estruendo sumiso se rinde, para triunfar con las galas de rendido.

Tiene qué se yo qué yerbas, qué conjuros, qué exorcismos, que ni la supo Medea, ni Tesalia las ha visto.

Tiene unos ciertos sonsaques, instrumentos atractivos, garfios del entendimiento y del ingenio gatillos que el raiGó $N$ más encarnado del dictamen más bien fijo del dictamen más bien fiJo que haya, de callar, harán salir la muela y el grito.

Por esto, como forzada, sin saber lo que me digo, os respondo, como quien escribe sin albedrío.

Vi vuestro romance, y una vez y otras mil visto, por mi falta JuRAdA, que JRAAJG= GRANJA JuzGo que No habla conmigo: porque yo bien me conozco, y no soy por quien se dijo aquello de haber JuNtAdo JNAAGR=GRANJA milAGRos y basiliscos.

Verdad es, que acá a mis solas, en unos ratos perdidos, a algunas vueltas de cartas borradas, las sobre-escribo, y para probar las plumas instrumentos de mi oficio, hice versos, como quien hace lo que hace no quiso.

Pero esto no pasó de consultar, acá conmigo, si podré entrar por fregona que cercenó desvelado

porque lo escribió dormido;

70

Talía me dio unas nesGas

GRANAJ=GRANJA

que sobRAron de uN corpiño

de unA Tabernaria Escena, cuando le AJustó el vestido; Melpómene, una bayeta de una Elegía que hizo

Séneca, que a Héctor sirvió de funesto frontispicio; Urania, Musa Estrellera, un astrolabio, en que vido las maulas de los planetas y las tretas de los Signos; y así, todas las demás que, con pecho compasivo, vestir al soldado pobre quisieron JuGAR coNmiGo. JGARNA = GRANJA

YA os he dicho lo que soy, ya he contado lo que he sido; no hay más que lo dicho, si en algo vale mi dicho.

Ya os he dicho lo que soy, ya he contado lo que he sido; no hay más que lo dicho, si en algo vale mi dicho.

Con que se siegue, que no puedo seR obJeto digno RJGANA = GRANJA

de los tAN mAl empleados versos, cuanto bien escritos.

Y no es humildad, porqué no es mi genio tan bendito que no tenga más filaucia que cuatrocientos Narcisos; mas no es tan desbaratado, aunque es tan desvanecido, que presuma que merece lo que nadie ha merecido.

De vuestra alabanza objeto no encuentro, en cuantos he visto, quien pueda serlo, si ya no se celebrare él mismo.

Si dios os hiciera humilde como tan discreto os hizo, y os ostentarais de claro como capáis de entendido, ya en mi Lógica vulgar os pudiera un silogismo que os hiciera confesar que ése fue solo el motivo, 


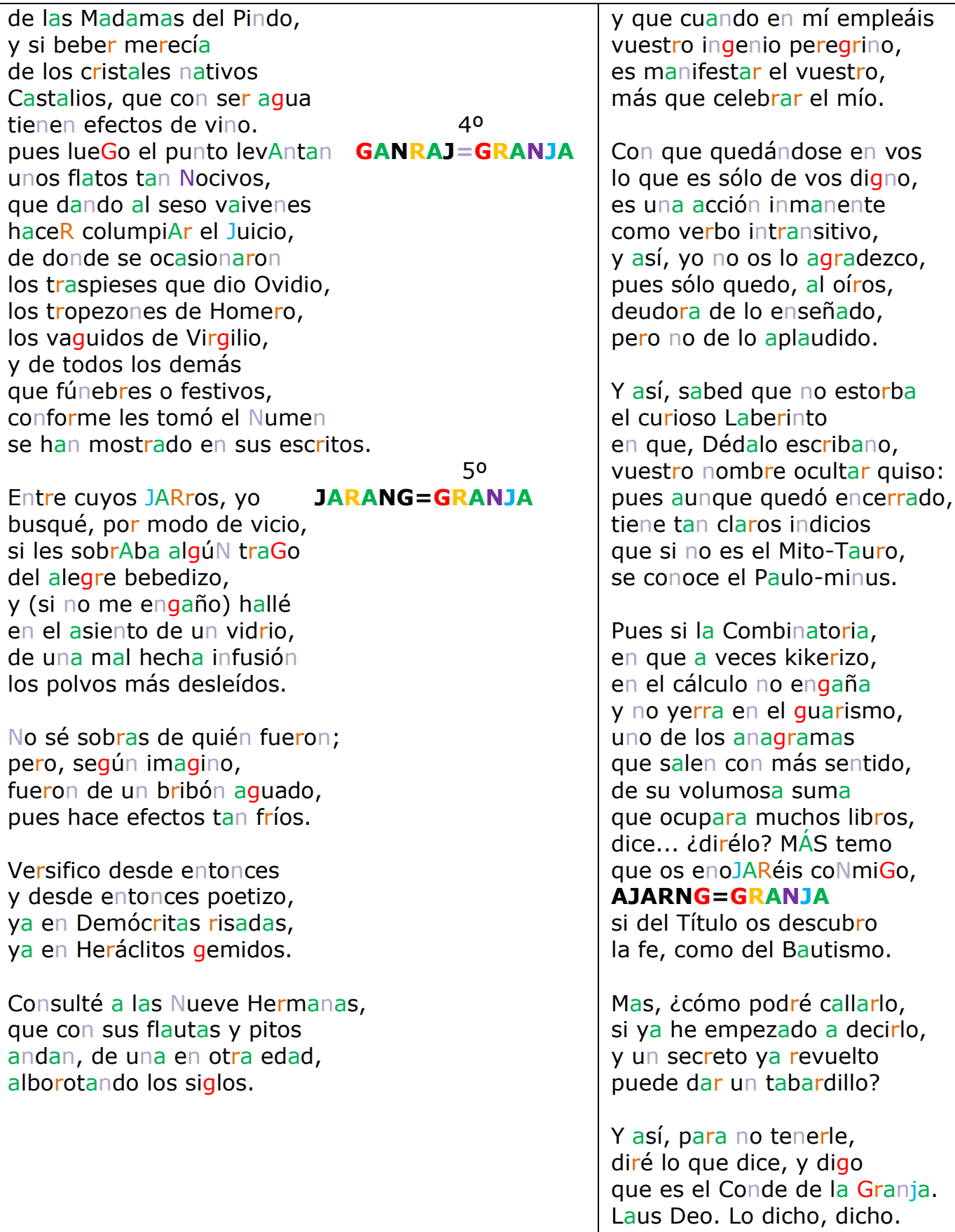

El pensamiento y las elaboraciones científicas de Kircher fueron determinantes para la monja, ya que tras de leer Musurgia Universalis, aplicó el concepto de la música y la literatura como arte numérico porque al ser las notas musicales 7 y las letras 28 , la creatividad está en las combinaciones que se logren. 


\section{Impacto de las lecturas de Nieremberg y de Kircher en sor Juana}

La razón de que estos dos importantes pensadores del siglo XVII fueran leídos y meditados por sor Juana era que la autora descubrió que ambos tenían tanto conocimiento científico como una gran admiración por el cosmos, y, paralelamente, era hombres unidos voluntariamente a una vida religiosa. Ellos pudieron pensar y dejar testimonio en sus escritos, ella también pretendía ser una mujer pensante y debería escribir algo más que literatura. El proyecto intelectual vital de sor Juana no fue precisamente el de escribir versos y comedias, sino el de alcanzar un estudio profundo de la Teología. Ella misma así lo expresa cuando se queja de su autodidactismo:

Ya se ve cuán duro es estudiar en aquellos caracteres sin alma, careciendo de la voz viva y explicación del maestro; pues todo este trabajo sufría yo muy gustosa por amor de las letras. iOh, si hubiese sido por amor de Dios, que era lo acertado, cuánto hubiera merecido! Bien que yo procuraba elevarlo cuanto podía y dirigirlo a su servicio, porque el fin a que aspiraba era a estudiar Teología. (OC, vol. IV, 447, ver. 294-301; cursivas mías)

El estudio y la enseñanza de Teología era aspiración intelectual imposible para una mujer, aun dedicada a la vida monacal; la monja de San Jerónimo mostraba su preferencia a las letras para velar su avidez intelectual orientada más a la indagación teológica. La Carta Athenagorica es una prueba fehaciente de su ingenio y sus amplios conocimientos de escolástica; con anterioridad escribió otros cercanos acaso a la teología, hoy por desgracia perdidos: El equilibrio moral que guardaba Carlos de Sigüenza y Góngora a la muerte de sor Juana (lo afirma Castorena y Ursúa en Fama y obras posthumas en 1700) y Las súmulas (según el Diccionario de la RAE: compendios o sumarios que contienen los principios elementales de la lógica, texto que para su autora pudiera sobrepasar el campo de esta ciencia). Además, como testimonio queda su prosa piadosa que hodierno es poco leída y menos citada. Sin embargo, habría que asentar que sus reflexiones teológicas pasaron a ser los temas de sus Autos y sus Villancicos, piezas que parecen simples festejos escenificables, pero que encubren sus anheladas cavilaciones teológicas.

Uno de los hallazgos más esclarecedores que aclaran del final de sor Juana es la Carta de Puebla - recientemente descubierta por el historiador Jesús Joel Peña Espinoza y dada a conocer por Alejandro Soriano Vallés-, misiva que fue la tan inesperada 'respuesta' de Fernández de Santa Cruz a la Respuesta a sor Filotea de la Cruz. ${ }^{4}$ La fecha de la Carta de Puebla es el 20 de marzo de 1691. Este texto contiene

${ }^{4}$ Esta misiva fue localizada por el historiador Peña Espinoza en la Biblioteca Palafoxiana de Puebla, junto con un borrador de la carta primera del obispo a sor Juana y otra carta en que se menciona que sor Juana 
categóricos párrafos sobre la venia obispal y el consejo fraternal para que sor Juana dedicara mayormente su tiempo a estudiar Teología (Soriano 2010, líneas 193-208):

[...] la aconsejo que estudie prácticamente dos horas al día en la Mística Teología; ¿No será lástima que una violenta propensión a las letras todas las ciencias, sea defraudada de la principal? Y que siendo grato empleo de su poderosa inclinación las Naturales escolástica Teología y Expositiva, ¿sea tan desgraciada la Mística, que no la deba algún suspiro? Las demás son ciencias, ésta es altísima Sabiduría, las demás ilustran el entendimiento, ésta da sabor a la voluntad, que bebiendo de la misma fuente de la Divinidad es enhebrada con los inefables deleites y vehemencia del amor de una ardentísima intuición, caliginosa claridad, altísimo conocimiento de Dios [...]

El obispo no manda que sor Juana se aleje de la Teología; sino por el contrario, insta a la monja a manera de exhortación fraternal, para que la estudie. Nótese la tachadura del inicio del texto: "que una violenta propensión a las letras todas las ciencias"; supresión del obispo que señala la atracción que sor Juana sentía por las ciencias, y que debió ser aún mayor que la que mostraba para las letras; aclaración que pareciera hacer de la literatura algo menos nocivo que la dedicación excesiva a lo científico. La recomendación venía de un afamado teólogo, el obispo Fernández de Santa Cruz, quien había publicado en latín estudios teológicos y bíblicos de gran aceptación. ${ }^{5}$ Su epitafio en la Catedral de Puebla ostenta esta frase: "Acutus, Profesus, Sacrorum Aenigmatum Extricator" (Profundo, Generoso, Intérprete Fiel de la Palabra de Dios).

\section{Conclusión}

Sorprende constatar que sor Juana estaba bien informada de las ideas de su siglo y que su pensamiento no distinguía entre literatura, ciencia o teología. Todo conocimiento era de su interés. Dos de los nombres de aquellos pensadores que influyeron en sus intereses intelectuales fueron: Kircher y Nieremberg. También el obispo de Puebla Fernández de Santa Cruz, era afamado teólogo y latinista, y grande fue su influencia en la monja, al incitarla al final de su vida a que dedicara horas de estudio a la Teología. Sor Juana no estaba sola, además de sus hermanas en religión

estudiaba griego, ¿Para qué querría sor Juana estudiar griego? La respuesta más convincente es que pretendía traducir textos griegos con los empeños de un/a exégeta.

5 Fernández de Santa Cruz escribió Consiliation Genesis et exodi locorum, Segovia 1571; Consiliation Librorum Pentateuchi, Levici, Numerorum et Deuteronomij, Lugduni, 1677; Conciliatio Librorum Josué, Judicum, Ruth, ac primi secundique Regum, Lugduni, 1689 y Ejercicio práctico de la Voluntad Divina, Puebla, 1681. 
y de familia, estaba acompañada por sus $\operatorname{libros}^{6}$, y como extensión, por el pensamiento de aquéllos hombres y mujeres que le compartían sus frutos del intelecto y del espíritu.

\section{References}

Bravo Arriaga, María Dolores, (2001), El discurso de la espiritualidad dirigida. Antonio Núñez de Miranda, confesor de Sor Juana. México, Universidad Nacional Autónoma de México-CONACYT.

Beuchot Puente, Mauricio, (2001), Sor Juana: una filosofía barroca: México: Universidad Autónoma del Estado de México, Centro de Investigación en Ciencias Sociales y Humanidades.

Paula Findlen, (2004), "A Jesuit's Books in the New Wolrld: Athanasius Kircher and His American Readers", in Athanasius Kircher: The Last Man who Knew Everything, EUA, Psychology Press.

Grossi, Verónica, (2007), Sigilosos v(u)elos epistemológicos en Sor Juana Inés de la Cruz. Madrid: Iberoamericana; Frankfurt: Vervuert.

Kircher, Athanasius, Musurgia universalis, 2 vols., 1650.

Kirk Rappaport, Pamela, (1998), Sor Juana Inés de la Cruz: Religion, Art, and Feminism. New York: Continuum Publishing Co.

Kirk Rappaport, Pamela, (1998), "Beauty And Love of God in the Work of Sor Juana Ines de la Cruz and Juan Eusebio Nieremberg, SJ.". (artículo inédito).

Juana Inés De La Cruz, (1951-1957), Sor, Obras completas, 4 vols, ed. de Alfonso Méndez Plancarte y Alberto G. Salceda.México: Fondo de Cultura Económica.

Nieremberg, José Eusebio, (1686), Curiosa filosofía y cuestiones naturales y Oculta filosofía (1631), en Obras filosóficas, éticas políticas y físicas. Sevilla: Lucas Martín de Hermosilla.

Nieremberg, José Eusebio, (1904), De la hermosura de Dios y su amabilidad por las Infinitas Perfecciones del Ser Divino. Madrid: Juan Sánchez. Madrid, 1641. También: Madrid: Biblioteca del Apostolado de la Prensa, 1904.

Nieremberg, José Eusebio, Obras escogidas del R.P. Juan Eusebio Nieremberg, Biblioteca de Autores Españoles, Madrid: Ediciones Atlas, 1957, vol. 2.

\footnotetext{
${ }^{6}$ Es falso que la monja fuera forzada a abandonar sus amados libros; es una fantasía para fabricar una mártir.Soriano Vallès ha publicado un documento que prueba que la biblioteca de sor Juana se puso a la venta por su propia voluntad y sin la interferencia del arzobispo Aguiar y Seijas; según lo testimonia el testamento de José de Lombeyda, sacerdote amigo de Sor Juana, a quien ella encargó vender su biblioteca (2013: 155-166).
} 
Olivares Zorrilla, Rocío, (2001), "La poética matemática de Sor Juana", en La producción simbólica en la América colonial: interrelación de la literatura y las artes. México, UNAM, Instituto de Investigaciones Bibliográficas, Seminario de Cultura Literaria Novohispana, CONACYT, 145-160. Se cita la versión existente en la Biblioteca Cervantes Virtual.

Olivares Zorrilla, Rocío, (2009), "Juan Eusebio Nieremberg y Sor Juana Inés de la Cruz", en Doctrina y Diversión en la cultura española y novohispánica. Madrid: Iberoamericana, 149-165.

Olivares Zorrilla, Rocío, (2010) "Apologética, mítica y mística en El Divino Narciso, de Sor Juana", en XXII Encuentro Nacional de Investigadores del Pensamiento Novohispano. Guanajuato. Noviembre de 2009. Memoria, Comp. De Aureliano Ortega Esquivel, Guanajuato, Universidad de Guanajuato, 149-189.

Paz, Octavio, (1994), Sor Juana Inés de la Cruz o Las trampas de la fe. México: FCE. Sabat-Rivers, Georgina, (1977), El "Sueño" de Sor Juana Inés de la Cruz: tradiciones literarias y originalidad. London: Tamesis Books Limited.

Schmidhuber, Guillermo, (2015), "Desciframiento de un criptograma de Sor Juana Inés de la Cruz: "Romance 50", eHumanista, vol. 31, 728-738. University of California at Santa Bárbara.

Schmidhuber, Guillermo y Olga Martha Peña Doria, (2016), Teatro y teología: Los tres Autos Sacramentales de sor Juana Inés de la Cruz. México: Universidad Claustro de Sor Juana y Bonilla Artigas Editores.

Strasser. Gerhard F., (2007), Out of Sync: Athanasius Kircher's Influence on Sor Juana's Writings. Barroco, vol. 1.2 verano.

Soriano, Alejandro, (2010), "Carta de Puebla", en Sor Juana Inés de la Cruz: Doncella del Verbo. México: Garabatos.

Tavard, George H., (1991), Juana Inés de la Cruz and the Theology of Beauty. The first Mexican Theology. London: University of Notre Dame.

Woods, Thomas, (2005), How the Catholic Church Built Western Civilization. Washington, DC: Regnery Publishing.Woods. 


\section{Summary}

\section{The ideas of Juan Eusebio Nieremberg and Athanasius Kircher in the work of Sor Juana Inés de la Cruz, the Novohispanic author}

The theological thought and the cosmological understanding by Juan Eusebio Nieremberg and Athanasius Kircher, famous Jesuits of the seventeenth century, had great influence on the writings of Sor Juana Inés de la Cruz (1648-1695), the summit female author of the Mexican Baroque. The Theology of Beauty of Nieremberg impacted her personal search, and beside, the writer herself quoted Kircher writing's extensively. This article cites the multiple times that his ideas made their mark on the writings of Sor Juana. The article includes an analysis of Sor Juana's romance 50 in which she encrypted a message using Kircher's musical techniques.

Keywords: Sor Juana Inés de la Cruz, Juan Eusebio Nieremberg, Athanasius Kircher, Novohispanic Literature, Hispanic American Baroque. 